\title{
Determination of the Stability Studies of the Sudanese Camel Insulin
}

\author{
Abdella Imam Abdella Baragob ${ }^{1}$, Waleed Hassan AlMalki ${ }^{1}$, Imran Shahid ${ }^{1 *}$, Hanouf Saeed Bafhaid ${ }^{1}$, \\ Fatimah Abdullah Bakhdhar ${ }^{1}$, Salwa Muhamed Khojali ${ }^{2}$, Samia Abdella ${ }^{2}$ \\ ${ }^{1}$ Department of Pharmacology and Toxicology, College of Pharmacy, Umm Al Qura University, Makkah, The kingdom of Saudi \\ Arabia; ${ }^{2}$ Faculty of Pharmacy, Khartoum University, Khartoum, Sudan. \\ Email: aeabaragob@yahoo.com,whmalki@uqu.edu.sa, ${ }^{*}$ iyshahid@uqu.edu.sa, fabakhdhar@uqu.edu.sa, hsbafhaid@uqu.edu.sa, \\ salwamuhamed@hotmail.com, samiah11@gmail.com
}

Received August $9^{\text {th }}, 2013$, revised September 12 ${ }^{\text {th }}, 2013$; accepted September $28^{\text {th }}, 2013$

Copyright (C) 2013 Abdella Imam Abdella Baragob et al. This is an open access article distributed under the Creative Commons Attribution License, which permits unrestricted use, distribution, and reproduction in any medium, provided the original work is properly cited.

\begin{abstract}
The main objective of the presented study was to characterize the stability of the Sudanese camel insulin after 6 months of its extraction, purification and formulation from the fresh pancreatic glands of the camel, slaughtered for local and export consumption. The stability and purity of the formulated insulin samples were compared to standard insulin samples that of the leading manufacturing companies using some analytical techniques such as HPLC, gel electrophoresis and atomic absorption. In another part of the study, the direct transfer method was used to accomplish sterility test by complete immersion of the insulin samples into thioglycollate and soybean medium. The data were presented as mean \pm S.E.M (standard error of means) for the comparison of zinc ( $\mathrm{mg} / \mathrm{units}$ ) and nitrogen (in percentage) concentrations in standard and testing camel insulin samples, respectively. Similarly, the linear equation was derived and the coefficient factors for standard and testing insulin samples were compared to determine the peak area and the concentrations of the camel insulin samples (mean \pm S.E.M) after HPLC elution. The $\mathrm{P}$ value, $\mathrm{P}<0.005$, was considered statistically significant. The stability study tests of the insulin samples (zinc and nitrogen contents, sterility, purity and potency test) reflect clearly their equivalence to standard insulin formulations in terms of stability. The results revealed that the stability of the various insulin samples from the camel insulin is not less than $25 \%$ of the time remaining until the preparations expire or six months earlier than the expiration date when compared to standard insulin samples.
\end{abstract}

Keywords: Analytical Techniques; Camel Insulin; Stability Studies; Shelf Life

\section{Introduction}

Stability is defined as the extent to which a product retains, within specified limits, and through its period of storage and use (i.e., its shelf-life), the same properties and characteristics that it possessed at the time of its manufacture [1]. There are at least five acceptable levels of stability for any dosage form to be evaluated before use [2]. First, Chemical stability which refers to the conditions maintained throughout the shelf life of the drug product and each active ingredient retains its chemical integrity and labeled potency within the specified limits. Second, physical stability describes the original physical properties including appearance, palatability, uniformity, dissolution and suspended ability. Third, microbiological stability which relates the effectiveness

"Corresponding author. of antimicrobial agents within the specified limits in the dosage form. Forth, therapeutic stability which determines the therapeutic effectivity of the dosage form and last the toxicity studies which determines the toxic effects of a particular dosage form. Stability of insulin matters a lot when marketed to use as a dosage form and its potency and stability must meet certain requirements before use. Stability of insulin is determined arbitrarily by subjecting a sample of insulin to a number of physical and chemical tests [3]. Similarly, insulin loses some of its physiologic activities due to some environmental change in storage conditions but if there is a considerable loss, e.g., $15 \%$ or more, then such a preparation is not considered suitable for general use [4]. Traces of certain metals, particularly zinc and nitrogen were found in some of the insulin unstable preparations. Therefore, it was assumed that the presence of these metals might be a 
factor affecting deterioration of insulin either upon prolonged standing at room temperature or upon subjection to a heat test [5]. The presented study describes an effort to determine the stability studies of unknown extracted, purified and formulated camel insulin preparations while comparing with standard insulin preparations.

\section{Materials and Methods}

\subsection{Materials}

All the chemicals and reagents used in the stability study of insulin samples were of pharmaceutical and analytical grades and the standard solutions, dilutions of the samples were prepared according to the reference book procedures.

\subsection{The Camel Insulin}

The provision of monograph of this study applies to the following camel insulin samples and these samples were prepared in the laboratory according to the standard procedures as mentioned in the reference books [6].

1) Soluble zinc insulin (soluble),

2) Insulin zinc suspension (amorphous),

3) Insulin zinc suspension (crystalline),

4) Insulin zinc suspension (mixed),

Vials of different insulin formulations (standard and samples) were stored in a refrigerator at $4^{\circ} \mathrm{C}$ and the entire quality control tests were performed after 6 months. We selected two subsample preparations named as "E" and " $D$ " from each type of testing camel insulin preparations (i.e., soluble, amorphous, crystalline and mixed).

\subsection{Methods}

The following quality control tests were performed to determine the stability of the extracted, purified and formulated camel insulin samples.

\subsubsection{Heat Test}

The main objective of the heat test is to ensure that all insulin preparations for stability under severe conditions. For this purpose, the standard and prepared insulin samples were subjected to heat test. The samples were put in a glass container and exposed to a temperature at $50^{\circ} \mathrm{C}-55^{\circ} \mathrm{C}$ and relative humidity of $75 \%$ for 10 days. The potency of the heated material was then compared either with a standard insulin or with a sample of the same preparation not exposed to the heat test. The samples were removed from the incubator once every day and made up to the proper dilution suitable for assay and kept in the refrigerator [7].

\subsubsection{Determination of Zinc Contents}

The zinc contents of the standard and testing insulin samples were determined by weighing $0.1 \mathrm{mg}$ of each sample and dissolved in $1 \mathrm{ml} \mathrm{HCl}(0.01 \mathrm{~N}$ solution) and read at $213 \mathrm{~nm}$ using a hollow cathode lamp as a source of radiation (atomic absorption). For camel insulin, we selected two insulin samples each weighing $0.1 \mathrm{mg}$ of soluble (D,E), crystalline (D,E) amorphous $(\mathrm{D}, \mathrm{E})$ and mixed camel insulin $(\mathrm{D}, \mathrm{E})$ respectively $[8]$.

\subsubsection{Determination of Nitrogen Content}

The nitrogen content of the standard and sample insulin samples were determined by weighing the samples and dissolved in $10 \mathrm{ml}$ of sulfuric acid with $11 \mathrm{~g}$ of catalyst for the process of digestion, then distilled with $15-20 \mathrm{ml}$ of Sodium Hydroxide (40\%), collected with a basic solution and titrated against $\mathrm{HC} 1$ (40.0\%). For camel insulin, we selected two insulin samples each weighing $0.016 \mathrm{mg}$ and $0.02 \mathrm{mg}$ of soluble (D), crystalline (D) amorphous (D) and mixed camel insulin (D) respectively. Similarly, two insulin samples each weighing $0.016 \mathrm{mg}$ and 0.02 $\mathrm{mg}$ were selected from soluble (E), crystalline (E) amorphous (E) and mixed camel insulin (E) was selected to determine their nitrogen contents [9].

\section{Study of Purity of Samples by Electrophoresis}

The purity of insulin samples was determined by gel electrophoresis. For this purpose we used Sebia ${ }^{\circledR}$ protein electrophoresis apparatus (Sebia ${ }^{\mathrm{TM}}$ cooperation, USA) and procedure was followed according to the manufacturer's protocol. The standard and camel insulin samples ran from the similar migration time showed a single band indicating a pure insulin sample without other protein impurities. The serum was used as a negative control [10].

\subsection{Sterility Test}

The sterility test of the camel insulins samples was performed in thioglycollate and the soybean medium by using the direct transfer method to check the microbial growth in the samples [11].

\subsection{Thioglycollate Medium Test}

Eight samples of thioglycollate medium each weighing $1.5 \mathrm{mg}$ were dissolved in $50 \mathrm{ml}$ of distilled water, gently heated and sterilized in an autoclave. Cooled the media after sterilization and added $5 \mathrm{ml}$ of each four camel insulin samples taken from soluble D,E, crystalline D,E, amorphous $\mathrm{D}, \mathrm{E}$ and mixed insulin $\mathrm{D}, \mathrm{E}$ respectively, thoroughly mixed and incubated at $30^{\circ} \mathrm{C}-35^{\circ} \mathrm{C}$ for overnight. Next day observed the samples for microbial growth in the media.

\subsection{Soybean Medium Test}

Eight samples of soybean medium each weighing $1.5 \mathrm{mg}$ 
were dissolved in $50 \mathrm{ml}$ of distilled water, gently heated and sterilized in an autoclave. Cooled the media after sterilization and added $5 \mathrm{ml}$ of each eight camel insulin samples taken from soluble D, E, crystalline D, E, amorphous $\mathrm{D}, \mathrm{E}$ and mixed insulin $\mathrm{D}, \mathrm{E}$ respectively, thoroughly mixed and incubated at $20^{\circ} \mathrm{C}-25^{\circ} \mathrm{C}$ for overnight. Next day observed the samples for microbial growth in the media.

\subsection{Potency Test of Insulin Carried out by HPLC}

The standard and camel insulin samples with concentrations of $0.1 \mathrm{mg} / \mathrm{ml}$, were used for insulin concentration and potency test by HPLC method [12]. The lyophilized material was dissolved in $0.2 \mathrm{M}$ ammonium phosphate, $\mathrm{pH} 4.0$, and $250 \mu \mathrm{l}$ were applied to a reversed phase HPLC column. An aliquot was directly counted to estimate the recoveries, The HPLC separations were performed with a Beckman model 332 liquid chromatograph equipped with a model 210 injector fitted with a $250-\mu 1$ loop. The column used was a DuPont Zorbax C-8 (4.6 $\mathrm{mm} \times 25 \mathrm{~cm} ; 6-\mu \mathrm{m}$ particle diameter) maintained at $40^{\circ} \mathrm{C}$ by a Bioanalytical Systems LC-22A temperature controller. Insulin was eluted from the column with a 0.2-M ammonium phosphate ( $\mathrm{pH} 4.0)$ /acetonitrile solvent system similar to that described previously and read with run time of 10 - 15 minutes. The peak area and capacity factors were calculated by the HPLC reading. The concentration of insulin by the HPLC method was reported as mean [13].

\section{Discussion}

Before the marketing and use of any insulin lot, its potency and stability must meet certain criteria and requirements. As it is an established fact that the labile drugs and vaccines if not stored under controlled conditions, may lose its potency and stability. Stability is arbitrarily determined by subjecting a sample of insulin to a heat test. Insulin thus treated loses some of its physiologic activities but if there is a considerable loss e.g., $15 \%$ or more, then such a preparation is not considered suitable for general use. Similarly, traces of certain metals, particularly zinc, copper, nitrogen and iron were found in some unstable insulin preparations; and it was therefore assumed that the presence of these metals be a factor affecting deterioration either upon prolonged standing at room temperature or upon subjection to a heat test. The deterioration of insulin upon standing and stored for a long time is a problem of considerable importance not only to the manufacturer but to the physician and in particular for the patients. In the presented study we analyzed different insulin samples, extracted, purified and prepared from Sudanese camel insulin for the stability, low in its ash content (free of such metals as zinc, nitrogen) and particularly for sterility and potency test after six months of their storage.

It is apparent from the results for the zinc contents of the testing and standard insulin preparations as shown in Table 1 that the zinc contents are not more than the amount stated in the individual monograph, as determined by atomic absorption spectrometry. Furthermore, the comparison of zinc concentrations of standard and testing insulin samples in Figure 1 showed that these figures are in compliance with Melville et al., [7] which demonstrated that the addition of $1 \mathrm{mg}$ of zinc per 1000 units neither increases the efficiency nor tends to prolong the duration of the hypoglycemic action of insulin on the blood sugar of normal fasting rabbits. Similarly, the nitrogen contents of the testing insulin meet the certain criteria as mentioned in the individual monograph and there is no considerable difference in percent nitrogen contents when compared to standard insulin preparations as shown in Table 2 and Figure 2. Protein gel electrophoresis is a reliable and an authentication method to determine the purity of protein samples. We used hydrofoil electrophoresis ( Sebia ${ }^{\mathrm{TM}}$ cooperation, USA) to determine and compare the purity of testing insulin samples with standard insulins according to the manufacturer protocol as shown in Figure 3. The results of the gel electrophoresis demonstrated clearly that the standard and sample insulin ran at the same migration time and appeared only as one band which indicated that the resulting samples were pure insulin samples, although the gel bands of camel insulin samples were slight weaker compared to standard insulin samples which might an indication that the samples had lost a little insulin potency. The concentration of the insulin samples further analyzed by HPLC method confirmed the results of gel electrophoresis. Microbial contamination is also a potential risk factor for the insulin and labile drug preparations and we confirmed that the testing insulin samples are free of any contamination by sterility test. The thioglycollate and soybean media showed no microbial growth in the testing insulin samples after $24 \mathrm{hrs}$ incubation period as shown in Table 3 .

The concentration of standard insulin preparations and testing camel insulin samples is shown in Tables $\mathbf{4}$ and $\mathbf{5}$ respectively. Figure 4, showed the calibration curve and corresponding linear equation relationship among different standard insulin samples. Figure 5, represented the HPLC elution profile for testing camel insulin samples and reproducible doublet can be seen at approximately 10 minutes for each sample respectively. For camel insulin samples, the percentage of peak area $($ mean \pm S.E.M) was $0.281 \pm 0.02 \%, 0.285 \pm 0.01 \%$, $0.290 \% \pm 0.02 \%$ and $0.345 \pm 0.03 \%$ respectively after $10-$ 12 minutes peak while for standard insulin preparations 


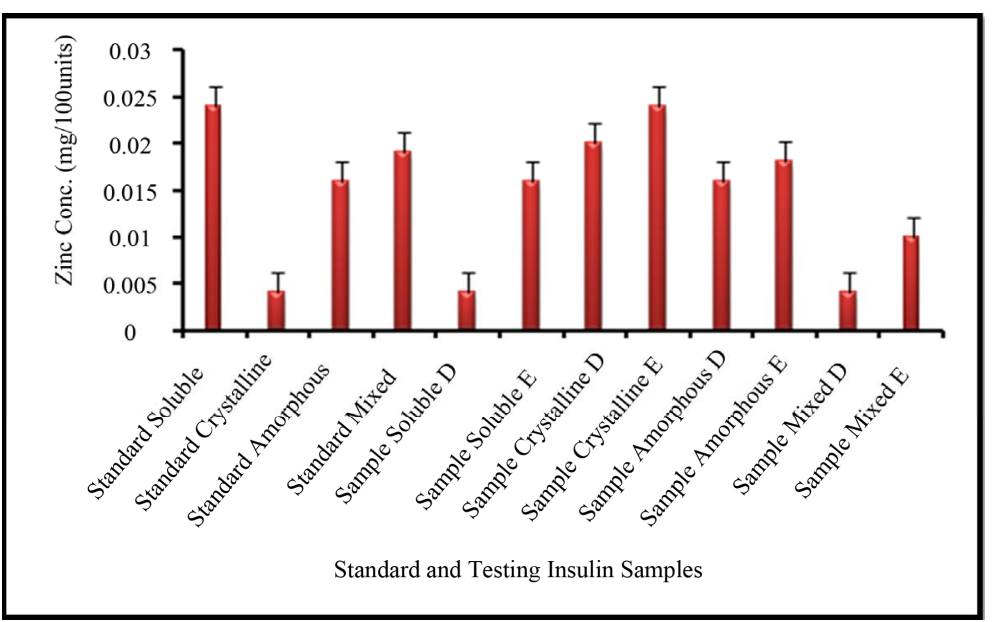

Figure 1. Comparison of zinc concentration between standard and testing camel insulin samples by atomic absorption method. The data were presented as mean \pm S.E.M. The $P$ value, $P<0.005$, was considered statistically significant.

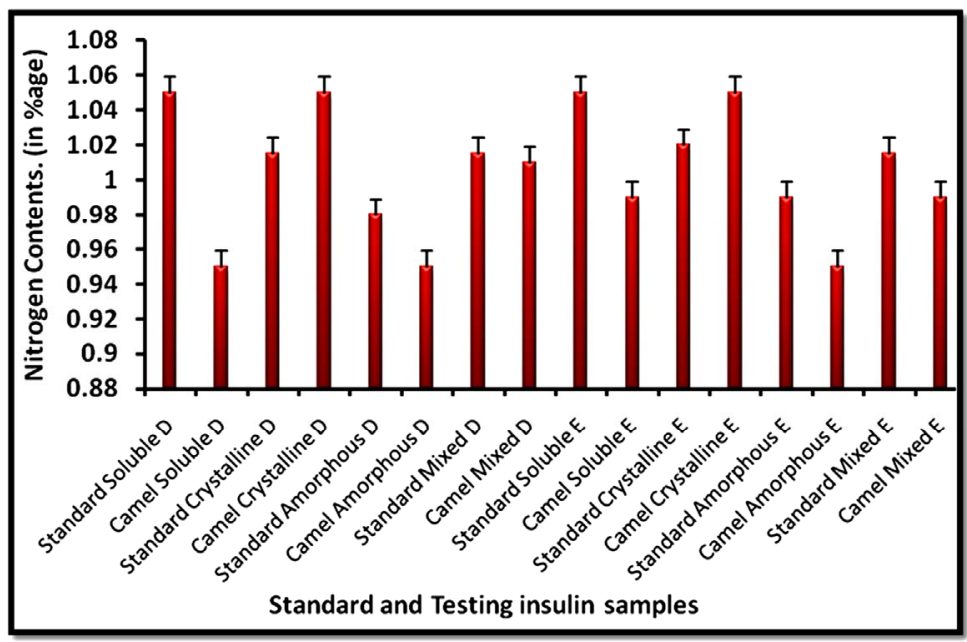

Figure 2. Nitrogen contents of standard and testing camel insulin Samples determined by acid base titration method. The data were presented as mean \pm S.E.M. The $P$ value, $P<0.005$, was considered statistically significant.

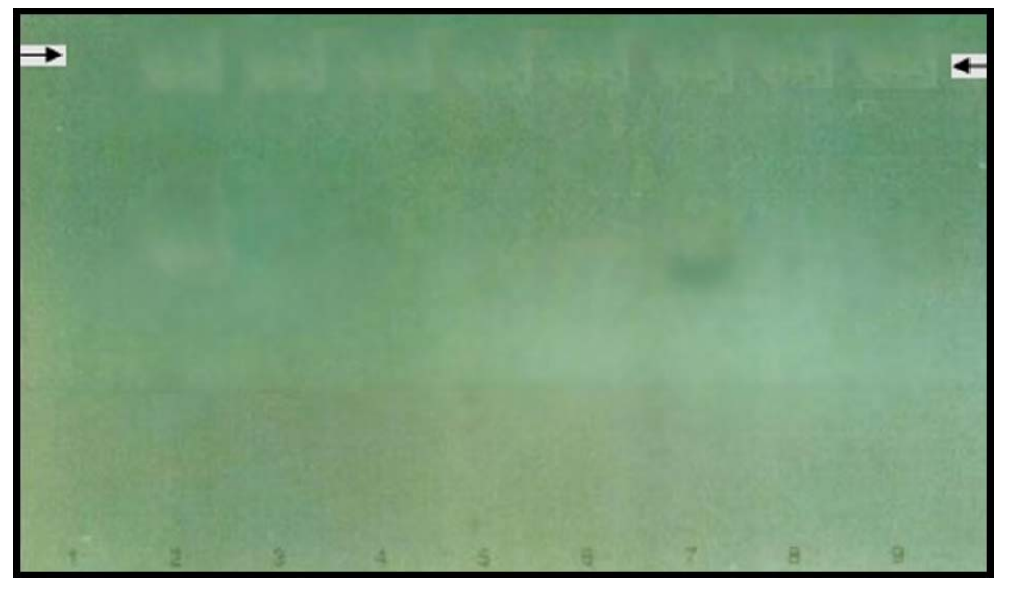

Figure 3. Hydragel electrophoresis of standard and testing camel insulin samples. Lane 1: negative control (serum), Lane 2: Standard insulin (soluble), Lane 3: standard insulin (crystalline), Lane 4: standard insulin (amorphous), Lane 5: standard insulin (mixed), Lane 6: Camel insulin (soluble), Lane 7: camel insulin (crystalline), Lane 8: camel insulin (amorphous), Lane 9: camel insulin (mixed). 
Table 1. Zinc contents of standard and camel insulin samples.

\begin{tabular}{|c|c|c|c|c|c|}
\hline $\begin{array}{l}\text { Standard insulin } \\
\text { Samples }\end{array}$ & $\begin{array}{l}\text { Weight } \\
(\mathrm{mg})\end{array}$ & $\begin{array}{c}\text { Zinc } \\
\text { (mg/100 unit) }\end{array}$ & $\begin{array}{l}\text { Camel insulin } \\
\text { samples }\end{array}$ & $\begin{array}{l}\text { Weight } \\
\text { (mg) }\end{array}$ & $\begin{array}{c}\text { Zinc } \\
\text { (mg/100 unit) }\end{array}$ \\
\hline & & & Soluble (D) & 0.1 & 0.004 \\
\hline Soluble & 0.1 & 0.024 & Crystalline (D) & 0.1 & 0.020 \\
\hline Crystalline & 0.1 & 0.004 & Crystalline (E) & 0.1 & 0.024 \\
\hline Amorphous & 0.1 & 0.016 & Amorphous (D) & 0.1 & 0.016 \\
\hline \multirow[t]{3}{*}{ Mixed } & 0.1 & 0.019 & Amorphous (E) & 0.1 & 0.018 \\
\hline & & & Mixed (D) & 0.1 & 0.004 \\
\hline & & & Mixed (E) & 0.1 & 0.010 \\
\hline
\end{tabular}

Table 2. Nitrogen contents of standard and testing camel insulin samples.

\begin{tabular}{|c|c|c|c|c|c|c|c|}
\hline Standard Insulin Samples & $\begin{array}{l}\text { Weight } \\
\text { (mg) }\end{array}$ & $\begin{array}{l}\text { Titration volume } \\
\qquad(\mathrm{ml})\end{array}$ & $\begin{array}{c}\text { Nitrogen } \\
\text { (\%age) }\end{array}$ & $\begin{array}{l}\text { Camel Insulin } \\
\text { Samples }\end{array}$ & $\begin{array}{c}\text { Weight } \\
(\mathrm{mg})\end{array}$ & $\begin{array}{c}\text { Titration } \\
\text { Volume (ml) }\end{array}$ & $\begin{array}{c}\text { Nitrogen } \\
\text { (\%age) }\end{array}$ \\
\hline Soluble (D) & 0.016 & 0.6 & 1.050 & Soluble (D) & 0.016 & 0.56 & 0.95 \\
\hline Crystalline (D) & 0.016 & 0.58 & 1.015 & Crystalline (D) & 0.016 & 0.60 & 1.05 \\
\hline Amorphous (D) & 0.016 & 0.70 & 0.980 & Amorphous (D) & 0.016 & 0.68 & 0.95 \\
\hline Mixed (D) & 0.016 & 0.72 & 1.015 & Mixed (D) & 0.016 & 0.55 & 1.01 \\
\hline Soluble (E) & 0.02 & 0.60 & 1.050 & Soluble (E) & 0.02 & 0.71 & 0.99 \\
\hline Crystalline (E) & 0.02 & 0.63 & 1.020 & Crystalline (E) & 0.02 & 0.58 & 1.05 \\
\hline Amorphous (E) & 0.02 & 0.71 & 0.990 & Amorphous (E) & 0.02 & 0.54 & 0.95 \\
\hline Mixed (E) & 0.02 & 0.73 & 1.015 & Mixed (E) & 0.02 & 0.65 & 0.99 \\
\hline
\end{tabular}

Table 3. Sterility test results of different camel insulin samples.

\begin{tabular}{clc}
\hline & & Thioglycollate medium \\
Camel insulin Samples & (Microbial growth) & No growth \\
\cline { 2 - 3 } Soluble (D) & No growth & No growth \\
Crystalline (D) & No growth & No growth \\
Amorphous (D) & No growth & No growth \\
Mixed (D) & No growth & No growth \\
Soluble (E) & No growth & Nowth growth \\
Crystalline (E) & No growth & No growth \\
Amorphous (E) & No growth
\end{tabular}

Table 4. Insulin concentration in standard samples.

\begin{tabular}{ccccc}
\hline & Samples & Conc. $(\mathrm{mg} / \mathrm{ml})$ & Area (\%) & C.F (Coefficient factor) \\
\hline 1 & Soluble & 0.1 & 1.057 & 0.0946073 \\
2 & Crystalline & 0.2 & 2.527 & 0.0791145 \\
3 & Amorphous & 0.3 & 4.807 & 0.0624029 \\
4 & Mixed & 0.4 & 8.117 & 2.2 \\
\hline
\end{tabular}

Table 5. Insulin concentration in different camel insulin samples.

\begin{tabular}{ccccc}
\hline & Samples & Conc. $(\mathrm{mg} / \mathrm{ml})$ & Area $(\%)$ & C.F (Coefficient factor) \\
\hline 1 & Soluble & 0.1 & 0.281 & 0.0196764 \\
2 & Crystalline & 0.1 & 0.285 & 0.0199537 \\
3 & Amorphous & 0.1 & 0.290 & 0.0199537 \\
4 & Mixed & 0.1 & 0.345 & 2.2 \\
\hline
\end{tabular}


the percentage of peak area was $1.057 \% \pm 0.03 \%$, $2.527 \% \pm 0.02 \%, 4.807 \% \pm 0.02 \%$ and $8.117 \% \pm 0.03 \%$ respectively after 10 - 15 minutes peak. Figure 6, described the comparison of coefficient factor among standard and testing insulin samples and demonstrated clearly low coefficient factor $(\mathrm{P}<0.005)$ for camel insulin samples an indication that the samples lost some potency after their storage. It was also concluded from the HPLC results that the camel insulin samples might also lose some potency (approx. 5\% - 10\%) after six month storage conditions. However, the results were compatible as previously described and met the standard criteria as mentioned in the individual monograph in standard books.

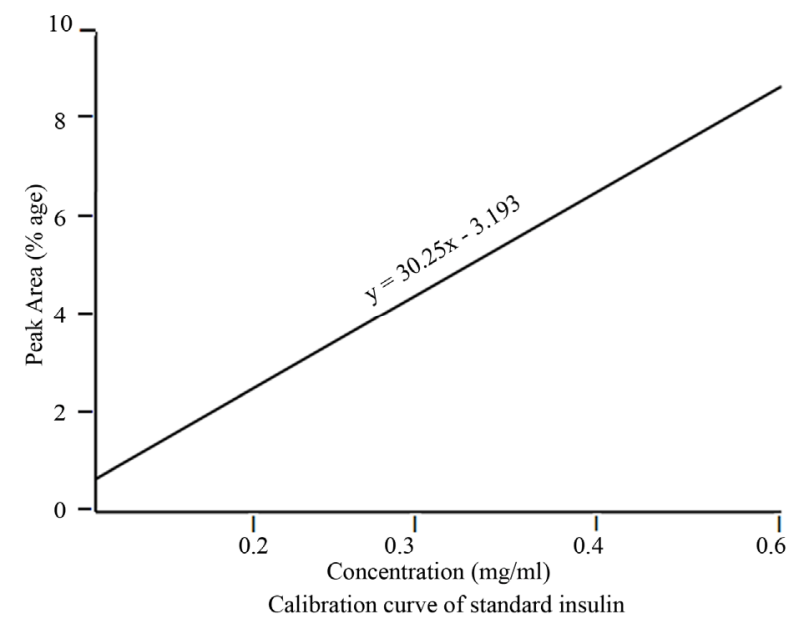

Figure 4. Calibration curve of standard insulin.

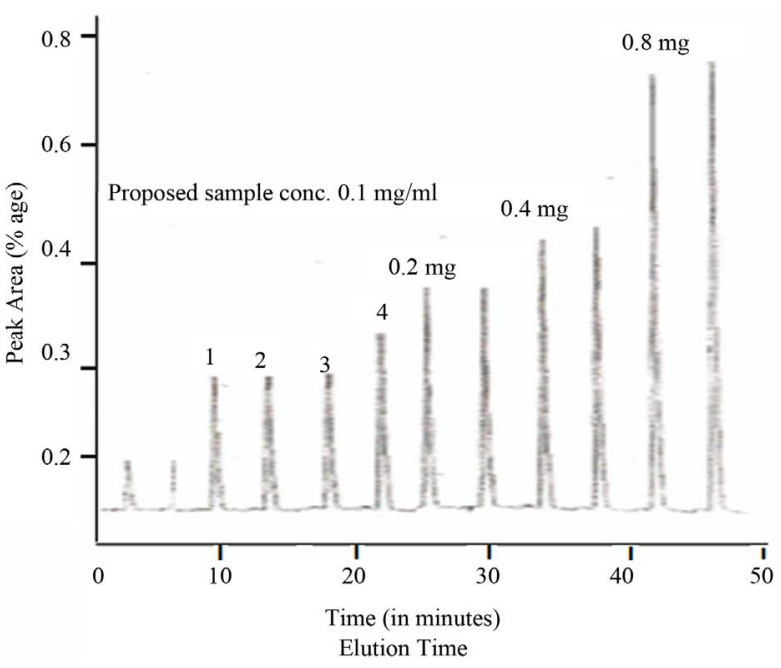

Figure 5. The HPLC elution profile for camel insulin samples: The peak area and elution time of testing camel insulin preparations, soluble (1), crystalline (2), amorphous (3) and mixed (4) respectively. The proposed testing insulin concentration was $0.1 \mathrm{mg} / \mathrm{ml}$, although the elution of higher insulin concentrations (i.e., $0.2 \mathrm{mg}, 0.4 \mathrm{mg}, 0.8 \mathrm{mg}$ respectively) was also shown in the figure.

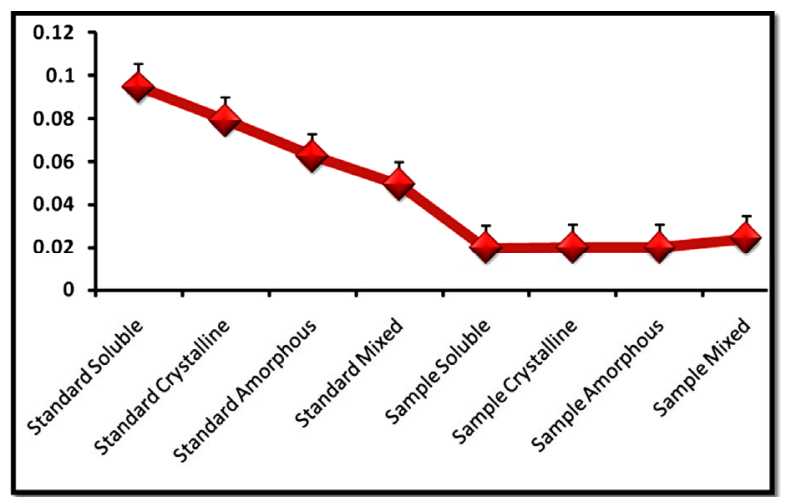

Figure 6. Comparison of coefficient factor against standard and testing insulin samples after HPLC elution. The data were presented as mean \pm S.E.M. The $P$ value, $P<0.005$, was considered statistically significant.

\section{Conclusion}

This work represents the stability studies of various formulated camel insulin preparations after their 6 months storage. In conclusion, after performing various stability tests the lose in insulin potency was not so much significant and product use date are not later than $25 \%$ of the time remaining until the product's expiration date.

\section{REFERENCES}

[1] L. H. Brown, K. Krumperman and C. J. Fullagar, "Outof-Hospital Medication Storage Temperatures: A Review of the Literature and Directions for the Future," Prehospital Emergency Care, Vol. 8, No. 2, 2004, pp. 200-206.

[2] M. M. Grajower, C. G. Fraser, J. H. Holcombe, M. L. Daugherty, W. C. Harris and M. R. De Felippis, "How Long Should Insulin Be Used Once a Vial Is Started," Diabetes Care, Vol. 26, No. 9, 2003, pp. 2665-2669. http://dx.doi.org/10.2337/diacare.26.9.2665

[3] P. S. Adams, R. F. Haines-Nutt and R. Town, "Stability of Insulin Mixtures in Disposable Plastic Insulin Syringes," The Journal of Pharmacy and Pharmacology, Vol. 39, No. 6, 1987, pp. 158-163.

http://dx.doi.org/10.1111/j.2042-7158.1987.tb06241.x

[4] C. Chandler, C. M. Gryniewicz, T. Pringle and F. Cunningham, "Insulin Temperature and Stability under Stimulated Transit Conditions," American Journal of HealthSystem and Pharmacology, Vol. 65, No. 10, 2008, pp. 953-963. http://dx.doi.org/10.2146/ajhp070347

[5] M. Pingel and A. Vølund, "Stability of Insulin Preparations," Diabetes, Vol. 21, No. 7, 1972, pp. 805-813.

[6] United States Pharmacopoeia Convention, "Parenteral, Preparation; Soluble Insulin, Insulin Zinc Suspension Crystalline, Insulin Zinc Suspension Amorphous, Insulin Zinc Suspension Mixed," United States Pharmacopoeia, 2000, pp. 807-808.

[7] S. Melville, M. Goodell and N. Arthur, "Factors Influencing the Stability of Insulin," Journal of Biological Chemistry, Vol. 117, No. 2, 1937, pp. 685-691. 
[8] British Pharmacopoeia, "Determination of Zinc Content by Atomic Absorption. The Method of Direct Calibration," Vol. 2, Appendix VIII, 2000, pp. 124-125.

[9] British Pharmacopoeia, "Determination of Nitrogen Content by Titration Method," Vol. 2, 2000, Appendix VIII, pp. 104-105.

[10] Sebia Instruction, "Test for Purity of Insulin Using Electrophoresis," 2003.

http://www.sebia-usa.com/products/html.

[11] United State pharmacopoeia Convention, "Sterility Test, Direct Transfer Method," United State pharmacopoeia, 2000, pp. 822-824.
[12] A. Oliva, J. Fariña and M. Llabrés, "Development of Two High-Performance Liquid Chromatography Methods for the Analysis and Characterization of Insulin and Its Degradation Products in Pharmaceutical Preparations," British Journal of Biomedical Sciences and Chromatography, Vol.749, No. 1, 2000, pp. 25-34. http://dx.doi.org/10.1016/S0378-4347(00)00374-1

[13] R. Gregory, S. Edwards and N. A. Yateman, "Demonstration of Insulin Transformation Products in Insulin Vials by High-Performance Liquid Chromatography," Diabetes Care, Vol. 14, No. 1, 1991, pp. 42-48. http://dx.doi.org/10.2337/diacare.14.1.42 